\title{
A COASTAL AREA MODEL CONSIDERING WAVE-CURRENT INTERACTION AND ITS APPLICATION TO WIDE-CRESTED SUBMERGED BREAKWATER
}

\author{
Masamitsu Kuroiwa ${ }^{1}$, Ahmed Khaled Seif ${ }^{2}$, Yuhei Matsubara ${ }^{3}$,Yasushi Ichimura ${ }^{4}$, \\ Hajime Mase $^{5}$ and Mazen Abualtayef ${ }^{6}$
}

\begin{abstract}
This study is concerned with development of a 3D morphodynamic predictive model for considering wave-current interaction by using wave action balance equation. The developed model was applied to model tests associated with a detached breakwater and wide-crested submerged breakwaters, and the influences of strong currents around the structures into wave height distribution and bathymetry change were investigated. Furthermore, the morphodynamics around the artificial reefs in the Uradome Beach, Tottori, Japan, was computed. From the computed results, a large scour hole due to strong rip-currents in the opening of the reefs was reproduced. The applicability of the model was confirmed.
\end{abstract}

Keywords: morphodynamic; submerged breakwater; rip-current; numerical simulation

\section{INTRODUCTION}

Wide-crested submerged breakwater, which is so-called "Artificial reef", is an effective structure for preventing sandy beach erosion due to wave and nearshore current actions, and for the landscape of sea-view in front of sandy beaches, especially Japan. Uradome beach in Tottori, which is a pocket beach facing the Sea of Japan, has been suffered from beach erosion. In order to prevent the beach erosion, two artificial reefs with the crest depth of $2 \mathrm{~m}$ and the crest width of $40 \mathrm{~m}$ were constructed in 1996, as shown in Fig.1. However, very large scour around a gap of the artificial reefs occurred due to strong rip currents at the gap, as shown in Fig. 2. Therefore, in order to take reliable countermeasures for preventing the large scour, maintaining stability of the submerged breakwaters, and evaluating the morphodynamics around the breakwaters, a coastal area model for considering the hydrodynamic in wave-current coexistence field such as the strong current generated at the gap is also required.

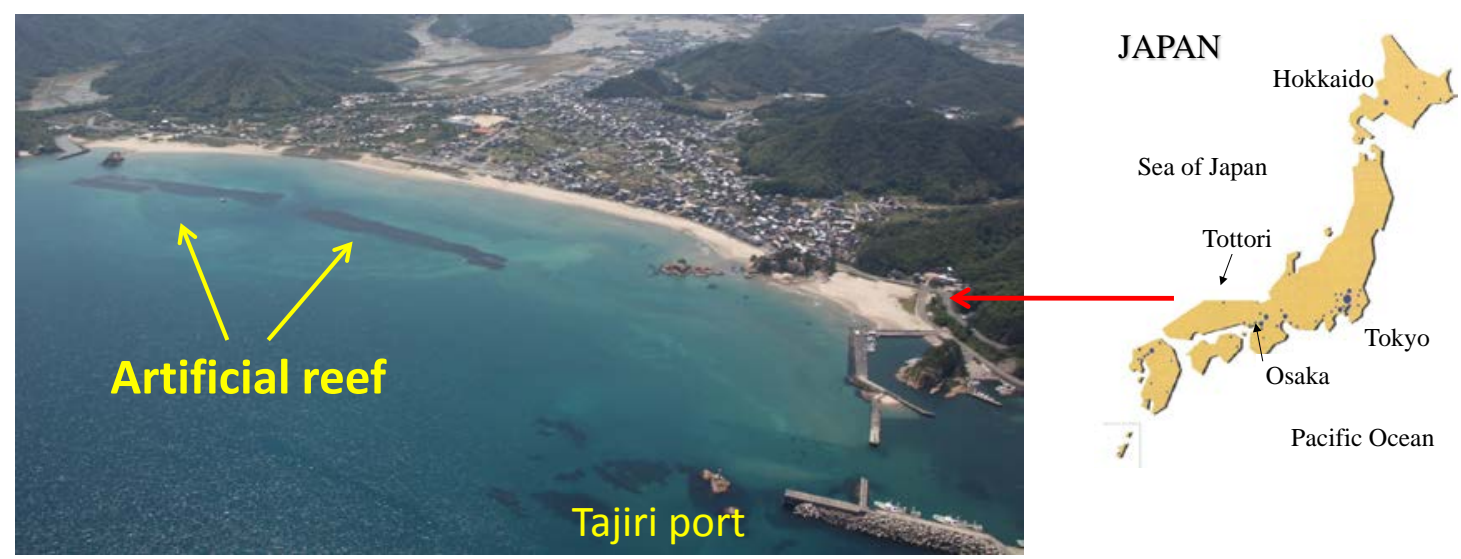

Figure 1. Aerial photo of artificial reef at Uradome sandy beach, Tottori, Japan.

Many three-dimensional beach evolution models have been proposed and then applied to practical evaluation of the construction of coastal structures, the accretion problems of the navigation channel of ports and so on. We have develop a coastal area model with shoreline change based on the quasi-three dimensional (Q-3D) nearshore current model (Kuroiwa et al., 2004), and applied to 3D morphodynamics around river-mouth (Kuroiwa et al.,2008) and after shoreface nourishments (Kuroiwa et al.,2010). However, the hydrodynamic module in the previous models, which is based on the wave

\footnotetext{
${ }^{1}$ Tottori University, Department of Civil Engineering, 4-101,Koyama,Tottori,680-8552, Japan

${ }^{2}$ National Water Resource Center, Coastal Research Institute, 15 El-Pharaana St. 21514, Alexandria, Egypt

${ }^{3}$ Tottori University, Department of Civil Engineering, 4-101,Koyama,Tottori,680-8552, Japan

${ }_{5}^{4}$ Mikuniya Corporation, 3-1-10, Naniwa-ku, Saiwai-chou, Osaka, 556-0021,Japan

${ }^{5}$ Disaster Prevention Research Institute, Kyoko University, Gokasho,Uji, Kyoto, 611-0011, Japan

${ }^{6}$ Department of Environmental Engineering, the Islamic University of Gaza, Palestine
} 
energy balance equation and the Q-3D nearshore current model, was not considering the wave-current interaction.

The purpose of this study is to develop a coastal area model for considering the wave-current interaction. In this study, the previous hydrodynamic model(e.g. Kuroiwa et al.,2002) is modified so as to be capable of considering the wave-current interaction. The wave action balance equation, which was presented by Mase et al.(2004), is employed to take into account the wave-current interaction. Model tests associated with coastal structures are conducted to investigate the performance of the presented model. Furthermore, the applicability of the model to a field site, which is Uradome beach, is investigated. In this application to the field site, we focused on the morphodynamic associated with the scour development between the artificial reefs in Uradome beach.

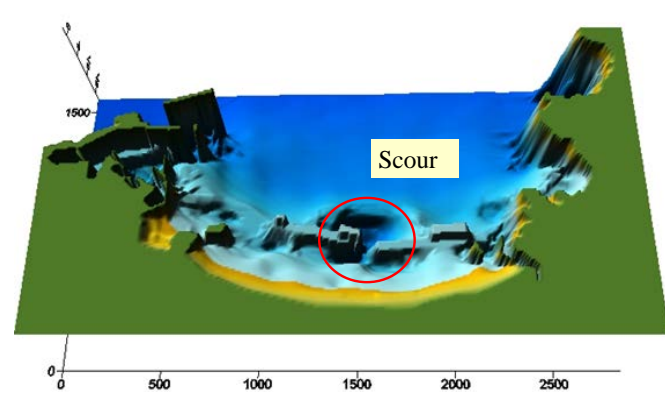

(a)September,2007

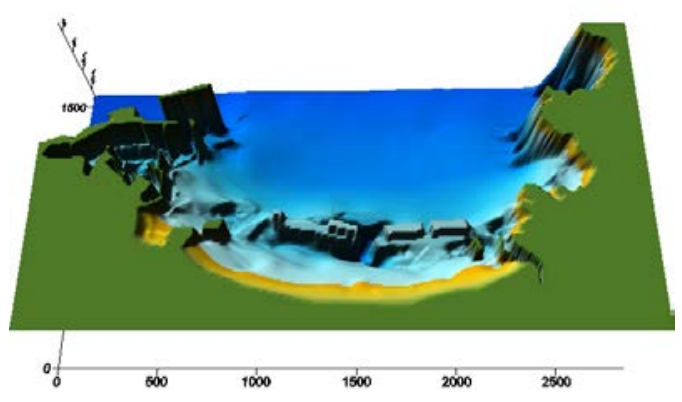

(b)Setember,2011

Figure 2. Measured bottom topography of Uradome sandy beach.

\section{NUMERICAL MODEL}

In this study, Multi-directional random wave model based on the wave action balance equation proposed by Mase et al.(2004) was newly added the previous 3D model presented by Kuroiwa et al.(2010). The presented model in this study consists of four modules as shown in Fig. 3. Computations of the wave and nearshore current field are iterated in order to consider the wave-current interaction.

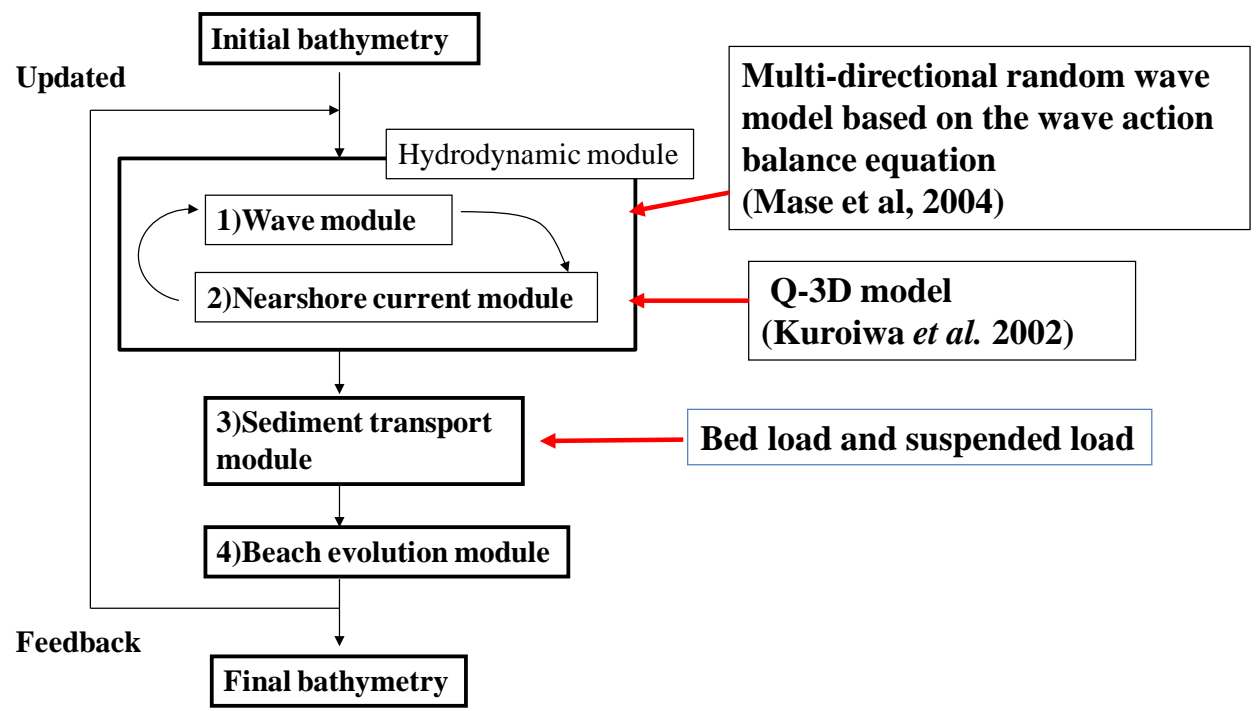

Figure 3. Computational flow of the presented three-dimensional morphodynamic model. 


\section{Wave module}

The wave module is based on the multi-directional random wave model, which is based on the wave action balance equation associated with energy dissipation terms for the wave breaking and wave diffraction (Mase et al., 2004). The governing wave action balance equation with the wave diffraction effects is

$$
\frac{\partial\left(C_{x} N\right)}{\partial x}+\frac{\partial\left(C_{y} N\right)}{\partial y}+\frac{\partial\left(C_{\theta} N\right)}{\partial \theta}=\frac{\kappa}{2 \sigma}\left\{\left(C C_{g} \cos ^{2} \theta N_{y}\right)_{y}-\frac{1}{2} C C_{g} \cos ^{2} \theta N_{y y}\right\}-\varepsilon_{b} N
$$

where $N$ is the wave action density, defined as the wave energy density divided by the angular frequency $\sigma$ relative to the current (Doppler shift). The horizontal coordinates are $x$ and $y$, and $\theta$ is the wave direction measured counterclockwise from the $x$-axis. $\kappa$ is the diffraction intensity parameter, which is set to 2.5. $C$ and $C_{g}$ are the wave celerity and group velocity, respectively. The characteristic wave velocities with respect to $x, y$, and $\theta$ coordinates are accordingly $C_{x}, C_{y}$ and $C_{\theta}$ as defined by

$$
\begin{gathered}
C_{x}=C_{g} \cos \theta+\tilde{U} \\
C_{y}=C_{g} \cos \theta+\tilde{V} \\
C_{\theta}=\frac{\sigma}{\sinh 2 k h}\left(\sin \theta \frac{\partial h}{\partial x}-\cos \theta \frac{\partial h}{\partial y}\right)+\cos \theta \sin \theta \frac{\partial \tilde{U}}{\partial x}-\cos ^{2} \frac{\partial \tilde{U}}{\partial y}+\sin ^{2} \theta \frac{\partial \tilde{V}}{\partial x}-\sin \theta \cos \theta \frac{\partial \tilde{V}}{\partial y}
\end{gathered}
$$

where $\tilde{U}$ and $\tilde{V}$ are the depth-averaged steady currents in the $x$ and $y$ direction, and $k$ is the wave number. $\sigma$ is the relative angular frequency with a relationship among the absolute angular frequency $\omega$, the wave number and the current velocity.

In Eq. (1), the parameterized function $\varepsilon_{b}$ describes the mean energy dissipation rate per unit horizontal area due to the wave breaking. The importance of this function was examined for four wave breaking formula by Zheng et al. (2008). In this study, the parameterized wave breaking function for wave energy dissipation is calculated from the following expression for bulk energy dissipation with the ambient current, which proposed by Chawla and Kirby (2002):

$$
\langle D\rangle=\frac{3 \lambda \rho}{32 \sqrt{\pi}} \sqrt{\frac{(g \bar{k})^{3}}{\tanh \bar{k} h}}\left(\frac{\bar{k}}{\gamma \tanh \bar{k} h}\right)^{2} \times H_{r m s}^{5}\left[1-\left\{1+\left(\frac{\bar{k} H_{r m s}}{\gamma \tanh \bar{k} h}\right)^{2}\right\}^{-5 / 2}\right]
$$

where $\langle D\rangle$ is the bulk energy dissipation by all breaking waves, $H_{r m s}$ is the root-mean-square wave height, and $\bar{k}$ is the wave number corresponding to the mean angular frequency $\bar{\sigma}$, and the scaling parameters $\lambda$ and $\gamma$ are set to 0.4 and 0.6 , respectively.

The wave breaking energy dissipation coefficient $\varepsilon_{b}$ is calculated as

$$
\varepsilon_{b}=\langle D\rangle /\left(0.125 \rho g H_{r m s}^{2}\right) \bar{\sigma}
$$

\section{Nearshore current module}

The nearshore current module is based on the Hybrid model with Q-3D mode and 2DH mode, proposed by Kuroiwa et al. (2006). The 2DH mode is based on the model of Nisimura(1988). The Q$3 \mathrm{D}$ is selected when the undertow filed in the surf zone should be estimated under stormy waves and then the Q-3D mode is based on the model using the fractional step method(e.g.Kuroiwa et al., 2002). The equations of motion and continuity are represented by

$$
\left.\begin{array}{l}
\frac{d U}{d t}=-g \frac{\partial \bar{\zeta}}{\partial x}-\frac{\partial R_{x x}}{\partial x}-\frac{\partial R_{x y}}{\partial y}+\frac{\partial}{\partial x}\left(v_{h} \frac{\partial U}{\partial x}\right)+\frac{\partial}{\partial y}\left(v_{h} \frac{\partial U}{\partial y}\right)+\frac{\partial}{\partial z}\left(v_{v} \frac{\partial U}{\partial z}\right) \\
\frac{d V}{d t}=-g \frac{\partial \bar{\zeta}}{\partial y}-\frac{\partial R_{y x}}{\partial x}-\frac{\partial R_{y y}}{\partial y}+\frac{\partial}{\partial x}\left(v_{h} \frac{\partial V}{\partial x}\right)+\frac{\partial}{\partial y}\left(v_{h} \frac{\partial V}{\partial y}\right)+\frac{\partial}{\partial z}\left(v_{v} \frac{\partial V}{\partial z}\right)
\end{array}\right\}
$$




$$
\left.\begin{array}{c}
\frac{\partial U}{d x}+\frac{\partial V}{\partial y}+\frac{\partial W}{\partial z}=0 \\
\frac{\partial \bar{\zeta}}{\partial t}+\frac{\partial \tilde{U}(h+\zeta)}{\partial x}+\frac{\partial \tilde{V}(h+\zeta)}{\partial y}=0
\end{array}\right\}
$$

where $U, V$ and $W$ are the local nearshore current velocities in the cross-shore $(x)$, alongshore $(y)$ and vertical (z) directions, respectively. $\tilde{U}$ and $\tilde{V}$ are the depth-averaged current velocities. $\bar{\zeta}$ is the mean water level. $R_{x x}, R_{x y}, R_{y x}$ and $R_{y y}$, represent the excess momentum fluxes based on the linear wave theory. $v_{v}$ and $v_{h}$ represent the turbulent eddy viscosity coefficients in the vertical and horizontal direction, respectively.

\section{Sediment transport and water depth change modules}

The total sediment transport considers bed load and suspended load. The water depth and shoreline changes are computed by the continuity equation, as follows:

$$
\frac{\partial h}{\partial t}=\frac{Q_{s}}{1-\lambda}+\frac{1}{1-\lambda}\left\{\frac{\partial}{\partial x}\left(q_{b x}+\varepsilon_{s}\left|q_{b x}\right| \frac{\partial h}{\partial x}\right)+\frac{\partial}{\partial y}\left(q_{b y}+\varepsilon_{s}\left|q_{b y}\right| \frac{\partial h}{\partial y}\right)\right\}
$$

where $h$ is the water depth, $q_{b x}$ and $q_{b y}$ are the bed loads. $\varepsilon_{s}$ is the dimensionless coefficient. The suspended load is determined by flux model, which is based on the two-dimensional advection diffusion equation, proposed by Sawaragi et al.(1986). $Q_{s}$ is the difference between the upward sediment flux $F_{z}$ and the downward flux $w_{f} c$, as given by

$$
\begin{gathered}
Q_{s}=F_{z}-w_{f} c \\
F_{z}=(1-\gamma) c_{0} \alpha w_{f}\left(\frac{u_{*}}{w_{f}}-1\right) \quad\left(\begin{array}{l}
u_{*} \geq w_{f}: \gamma=0 \\
u_{*} \leq w_{f}: \gamma=1
\end{array}\right.
\end{gathered}
$$

where $\alpha(0 \leq \alpha \leq 1.0)$ is the dimensionless coefficient, $c_{0}$ is the concentration at reference point, $c_{0}=0.347 N_{c}^{1.77}$.

$$
N_{c}=\frac{0.688 \hat{u}_{w}^{2}}{1.13(s-1) g w_{f} T}
$$

$\hat{u}_{w}$ is the maximum orbital velocity at bottom, $s$ is the specific gravity of sand, $T$ is the wave period. $c$ is determined by solving the following advection diffusion equation, as given by,

$$
\frac{\partial c}{\partial t}+\tilde{U} \frac{\partial c}{\partial x}+\tilde{V} \frac{\partial c}{\partial y}=\frac{\partial}{\partial x}\left(\varepsilon_{x} \frac{\partial c}{\partial x}\right)+\frac{\partial}{\partial y}\left(\varepsilon_{y} \frac{\partial c}{\partial y}\right)+\frac{Q_{s}}{\bar{\eta}+h}
$$

The bed load is estimated using the bottom friction factor proposed by Watanabe et al(1986). The total bed loads are given by

$$
\overrightarrow{q_{b}}=\overrightarrow{q_{w}}+\overrightarrow{q_{c}}=\left\{\begin{array}{l}
q_{b x}=q_{w x}+q_{c x} \\
q_{b y}=q_{w y}+q_{c y}
\end{array}\right\}
$$

$\overrightarrow{q_{w}}$ is due to wave orbital velocities at bottom. $\overrightarrow{q_{c}}$ is due to steady current velocity. These are estimated by

$$
\left.\begin{array}{rl}
\overrightarrow{q_{w}} & =A_{w}\left(u_{*}^{2}-u_{*_{c}}^{2}\right) \overrightarrow{\hat{u}_{w}} / g \\
\overrightarrow{q_{c}} & =A_{c}\left(u_{*}^{2}-u_{*_{c}}{ }^{2}\right) / g
\end{array}\right\}
$$

where $A_{w}$ and $A_{c}$ are dimensionless coefficients, $u_{*}$ is the friction velocity, $u_{*_{c}}$ is the critical friction velocity, and $\vec{U}$ is the steady current vector. In case of the Q3D mode use, the bed load is determined by using bottom current velocities. The coefficients $A_{w}$ and $A_{c}$ are given by a function of the median diameter $d_{50}$ (Shimizu et al, 1996) as 


$$
\left.\begin{array}{c}
B_{w}=C_{w}\left(\sqrt{d_{50}} / w_{f}\right)^{3} \\
A_{w} / B_{w}=w_{f} \sqrt{0.5 f_{c w}} /\left\{(1-\lambda) s \sqrt{s g d_{50}}\right) \\
A_{c}=\beta A_{w}
\end{array}\right\}
$$

where $C_{w}$ is a dimensionless coefficient, $w_{f}$ is the fall velocity of sand, $f_{c w}$ is the sea-bottom friction factor, $\lambda$ is the porosity of the bed, and $s$ is the specific gravity in the water.

\section{MODEL TESTS}

In order to investigate the influence of computation of the wave-current interaction into morphodynamics, the presented model was applied to bathymetry changes due to strong currents around a detached breakwater and two submerged breakwaters. In computations of nearshore current for these model tests, the Q-3D mode was used.

\section{Detached breakwater}

Computational domain was set in an area of $800 \mathrm{~m}$ in the alongshore direction and $600 \mathrm{~m}$ in the cross-shore direction. The initial depth contours is parallel to shoreline. The beach slope is $1 / 50$. A detached breakwater with the length of $100 \mathrm{~m}$ was arranged in the computational area. Significant wave height and period were $1.5 \mathrm{~m}$ and $7.0 \mathrm{~s}$, respectively. Wave direction was normal to shoreline. In order to indicate the difference between the previous model and the presented model, computed results without and with the wave-current interaction are shown in the left and right in Fig. 4, respectively. In Fig.4, upper and middle figures are wave field and the depth-averaged steady current field against the initial bathymetry, respectively. The bathymetry changes after 20 days are shown in lower figures.

From the computed wave height distribution behind the detached breakwater with the interaction is remarkably different from that without the interaction. In the computed result with the interaction, the value of the significant wave height became large by the influence of seaward current velocity behind the breakwater.

In the computations of bathymetry change without the interaction a doubled-salient was formed, whereas a single salient was formed in the computation of bathymetry with the interaction. The presented model with the interaction may provide qualitatively reasonable results.

\section{Artificial reef}

The initial bathymetry used in this computation of artificial reef is represented in Fig.5. The computational domain was an area of $1000 \mathrm{~m}$ in the alongshore direction and $600 \mathrm{~m}$ in the cross-shore direction. As shown in Fig. 5, two artificial reefs with the crest depth of $2 \mathrm{~m}$ were arranged around the water depth $3.5 \mathrm{~m}$. Wave height and period at offshore boundary were set to $2 \mathrm{~m}$ and $8 \mathrm{~s}$, respectively.

From the computed results of bottom currents in Fig.6, rip-current occurred at the gap of the artifical reefs. In the computed results without the interaction, Undertow currents were reporoduced between the arificirial reef and shoreline. It is found that the magunitude and direction of the current vectors with wave-current interaction are different from those without the interaction. The wave height at the gap was increased by the existence of the rip-current. On the other hand, the wave height over the crest of the artificial was decreased due to the strong shoreward current. From comparison of bathymetry change, the computed bottom topogrphy with the wave-current interaction is different from that without the wave-current interaction. The contour lines of $2 \mathrm{~m}, 1 \mathrm{~m}$ and shoreline are especially different. In case of the interaction, erosion area(blue area) around shoreline from $y=300 \mathrm{~m}$ to $700 \mathrm{~m}$ is smaller than that without the inertaciton.This is due to the discrepancy of the magunitude and direction of steady current vectors. 

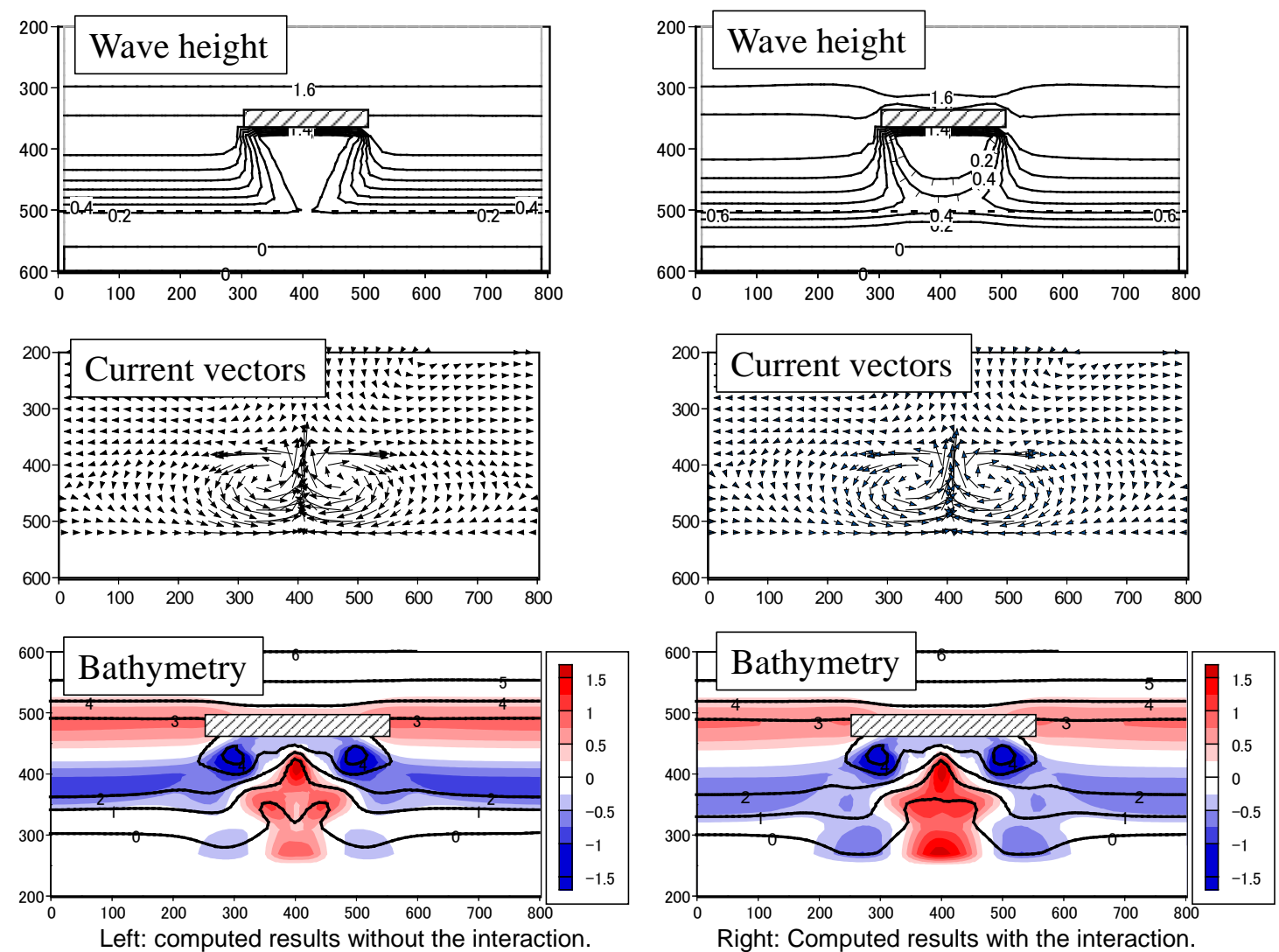

Figure 4. Computed results for a detached breakwater without and with wave-current interaction.

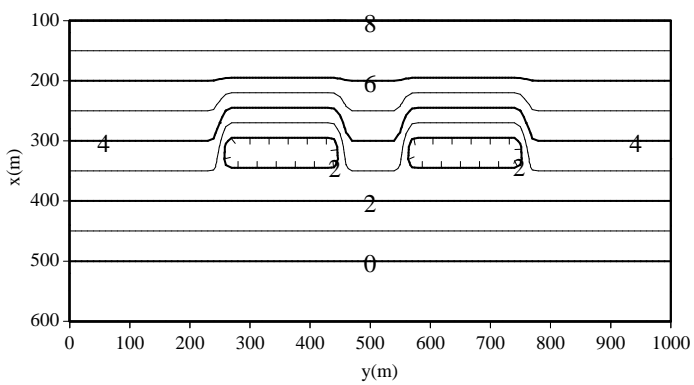

Input wave data

Significant wave height : Hs=1.5m

period: $T s=7.0 \mathrm{~s}$

Figure 5. Measured bottom topography of Uradome sandy beach. 

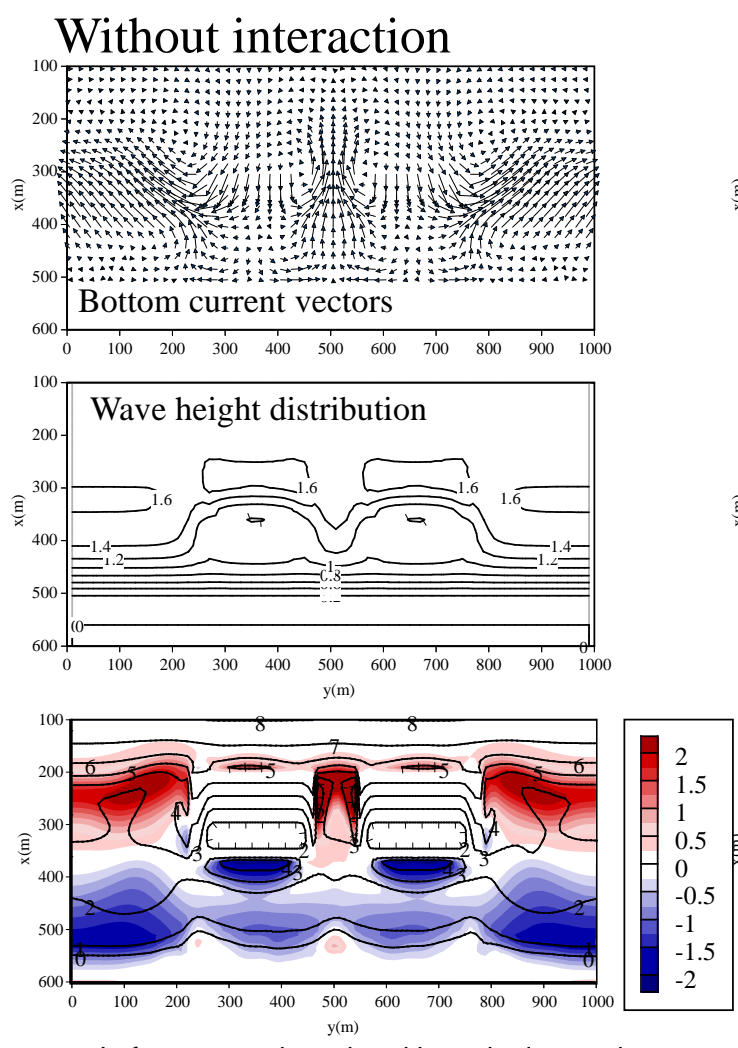

Left: computed results without the interaction.
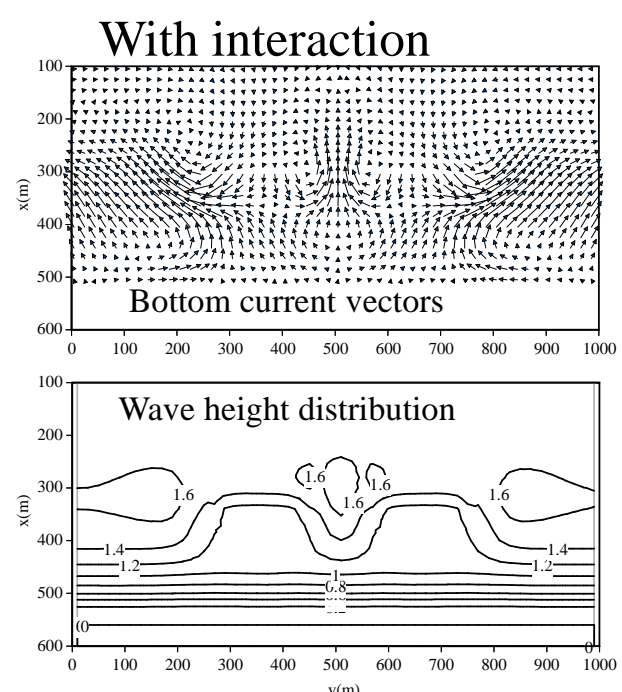

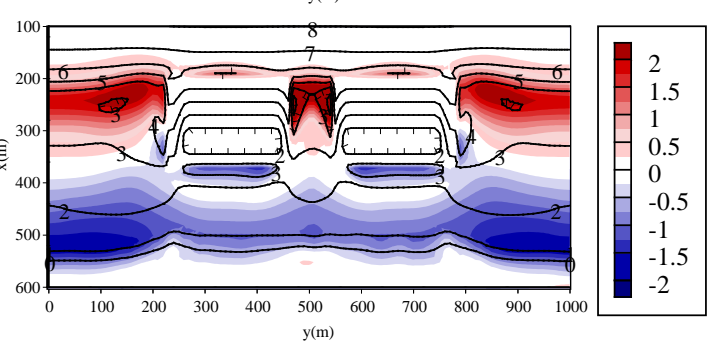

Right: Computed results with the interaction.

Figure 6. Computed results for two artificial reefs without and with wave-current interaction (Upper: wave field, Center: steady current filed, Lower; bathymetry after 20days).

\section{MODEL APPLICATION TO A FILED SITE}

In order to investigate the applicability of the presented 3D morphodynamic model, the computation of the bathymetry change in Uradome sandy beach with two artificial reefs was carried out.

\section{Bathymetry changes at Uradome beach}

Figs.7 (a) and (b) show survey results in Sep. 2007 and Mar. 2008, respectively. In Fig.7 (b), the erosion(blue area) and accretion(red area) obtained from the difference between Sep.,2007 and Mar.2008 are illustrated. In the period from Sep. 2007 to Mar. 2008, a part of the crest width and depth were improved to more prevent the beach erosion. However, after the improvement, a large scour hole was generated, as shown in the blue area between two artificial reefs in Fig.7(b).

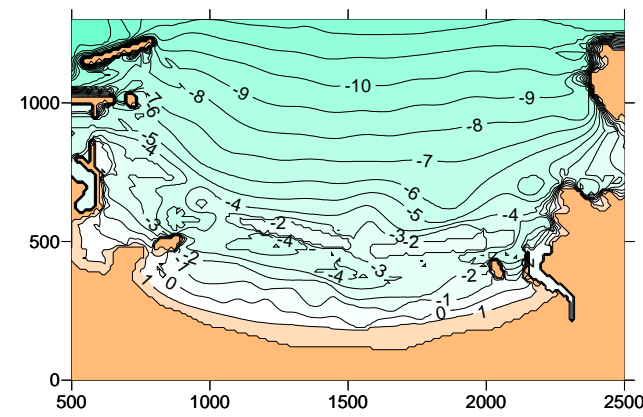

(a)Measured bathymetry in Sep. 2007.

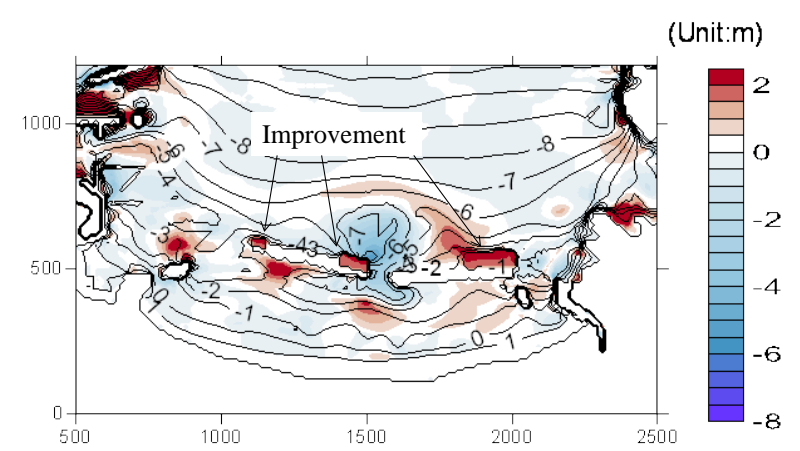

(b) Measured bathymetry in Mar. 2008

Figure 7. Measured bathymetries at Uradome beach in Sep. 2007 and Mar. 2008. 


\section{Computational domain and wave conditions}

The survey results used in this computation were the depth data measured in Sep., 2007 and Mar., 2008, as shown in Figs.7.(a) and (b). The initial bathymetry was set to an area of $2.0 \mathrm{~km}$ in the alongshore direction and $1.2 \mathrm{~km}$ in the cross-shore direction, as shown in Fig. 8. The bathymetry change after 6 months was computed. The computed result after 6 months was compared with the survey result in Fig.7(b).

The order of wave conditions was made as represented in Fig.9 and Table 1. The wave conditions are based on the wave data measured at the depth of $30 \mathrm{~m}$ in offshore area of Tottori port. The prediction after 6 months can correspond to the period of 122 days as shown in Fig.9, by neglecting the wave height less than $1 \mathrm{~m}$. The grid $\Delta x$ and $\Delta y$ in the computations were set to $5 \mathrm{~m}$. In this model application, Q3D mode was used under stormy wave condition, the wave height larger than 3m,in Step(3) and (11).

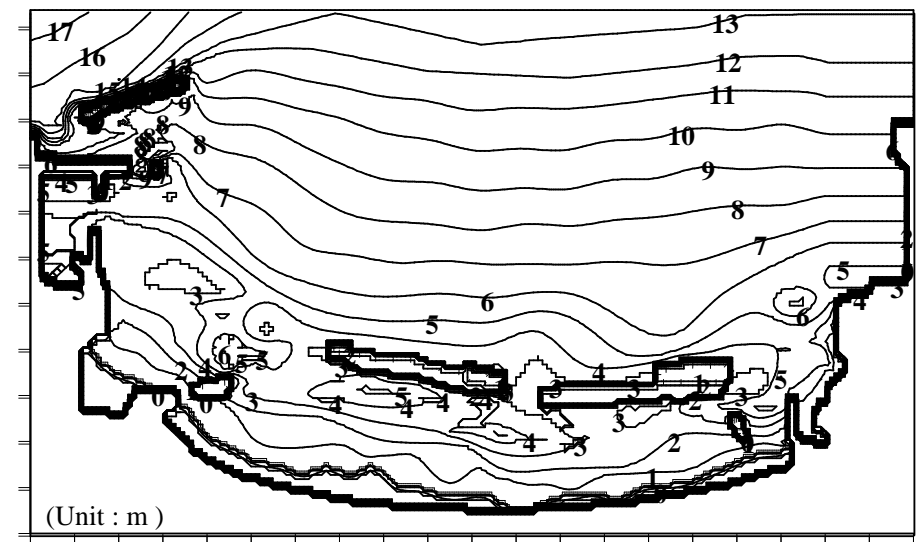

Figure 8. Initial bathymetry of computation (from survey results conducted in Sep.,2007).

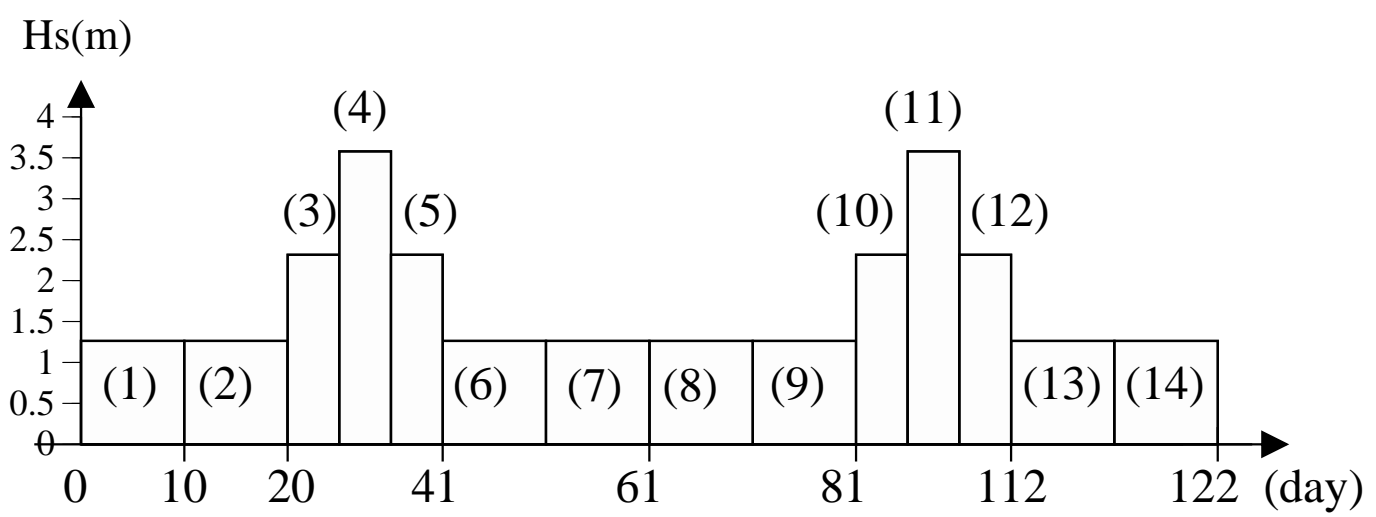

Figure 9. Input wave height time history with two stormy wave conditions.

\begin{tabular}{|c|c|c|c|c|}
\hline \multicolumn{5}{|c|}{ Table 1. Input wave data (Significant wave height, period and direction) at each step. } \\
\hline Step & $\mathrm{Hs}(\mathrm{m})$ & $\mathrm{Ts}(\mathrm{s})$ & direction & Duration time (days) \\
\hline (1), (2), (6)-(9),(13),(14) & 1.4 & 6.7 & $-7.79(\mathrm{~N})$ & 10 \\
$(1),(5),(10),(12)$ & 2.4 & 7.1 & $16.0(\mathrm{NNW})$ & 7.5 \\
$(4),(11)$ & 3.7 & 9.7 & $15.1(\mathrm{NNW})$ & 5 \\
\hline
\end{tabular}




\section{Computed results}

In this study, we focused on the morphodynamcs in the vicinity of the reefs, especially, scour hole formed between the reefs.

Figures 10 and 11 show computed results of wave height distribution and nearshore current field. In these figures, (a), (b) and (c) corresponds to the results after step(1),(3) and (4), respectively. Fig.12 shows computed result, corresponding to the bathymetry change after 6 months. From the computed results, strong shoreward currents around the improved crest occurred, whereas strong rip currents between the reefs were generated. It was found that the magnitude of the current became large under stormy wave. As shown in Fig.12, a large score hole was formed by the existence of the strong ripcurrents. The computed bathymetry change around the reefs qualitatively agrees with the measured bathymetry in Fig.7(b). Comparing with the scour hole, although the presented model can reproduce, the depth of the score hole is smaller than the measured score hole.

In this application, the computed wave height and current distributions were not compared with the field data. The computed waves and currents should be compared with field data, and then the wave and nearshore current modules should be calibrated and verified in detailed.

\section{CONCLUSIONS}

In this study, a 3D morphodynamic model for considering the wave-current interaction was developed. Firstly, model tests associated with a detached breakwater and wide-crested submerged breakwaters were carried out in order to investigate the performance of the model. Secondly, a model application to a field site, which is a pocket beach with artificial reefs, was conducted in order to investigate the applicability of the presented model. From the computed results, some conclusions are derived as follows:

\section{Model test}

From the results associated with a detached breakwater, a single salient was formed behind the detached breakwater by considering the wave-current interaction in the wave and nearshore current modules. The computed result is better than that without the interaction.

For submerged breakwater model test, the magnitude and direction of current vectors with the interaction behind the submerged breakwater differ from those without the interaction, furthermore, the computed bathymetry change also differ from result without the interaction.

\section{Field application}

It was confirmed that the presented model can simulate nearshore current field around the artificial reefs. Especially, strong rip-currents at the gap of the reefs can be reproduced. And a score hole at the gap was also reproduced.

From comparison with the measured bathymetry change at Uradome beach, the computed bathymetry change around the reefs was qualitatively agreement with the measured data. However, the depth of the computed score hole was smaller than the measured scour hole.

\section{Future work}

In this study, computed wave height distribution and nearshore current filed were not compared with the field data. The accuracy of the presented model should be reexamined in detailed. Filed investigations associated with waves and currents have already conducted at Uradome beach. We will calibrate and verify the presented model by using the field data.

\section{ACKNOWLEDGMENTS}

The present study was conducted as a part of the cooperative study between Tottori University and Tottori Prefecture, Japan. 


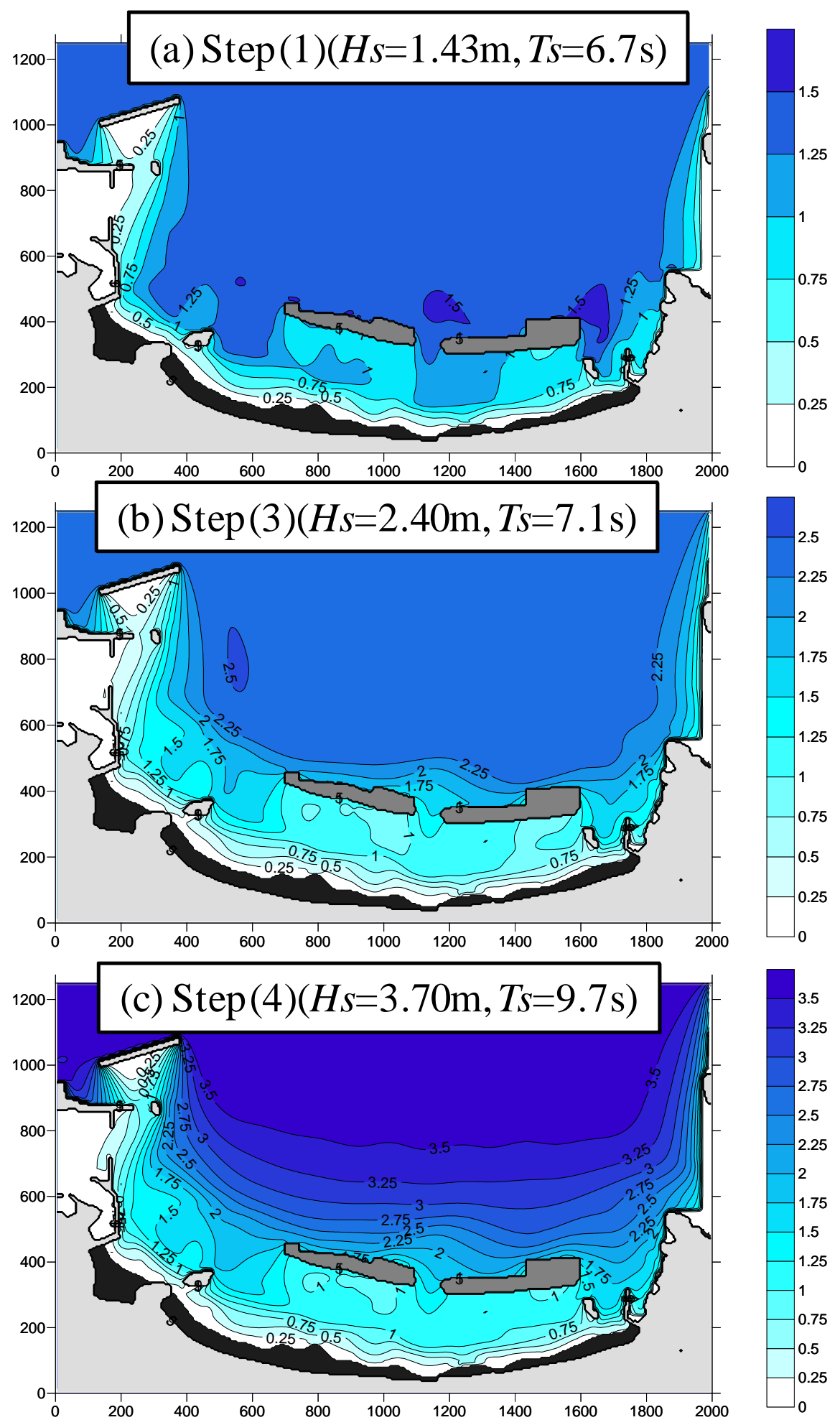

Figure 10. Computed results of significant wave height distribution. 


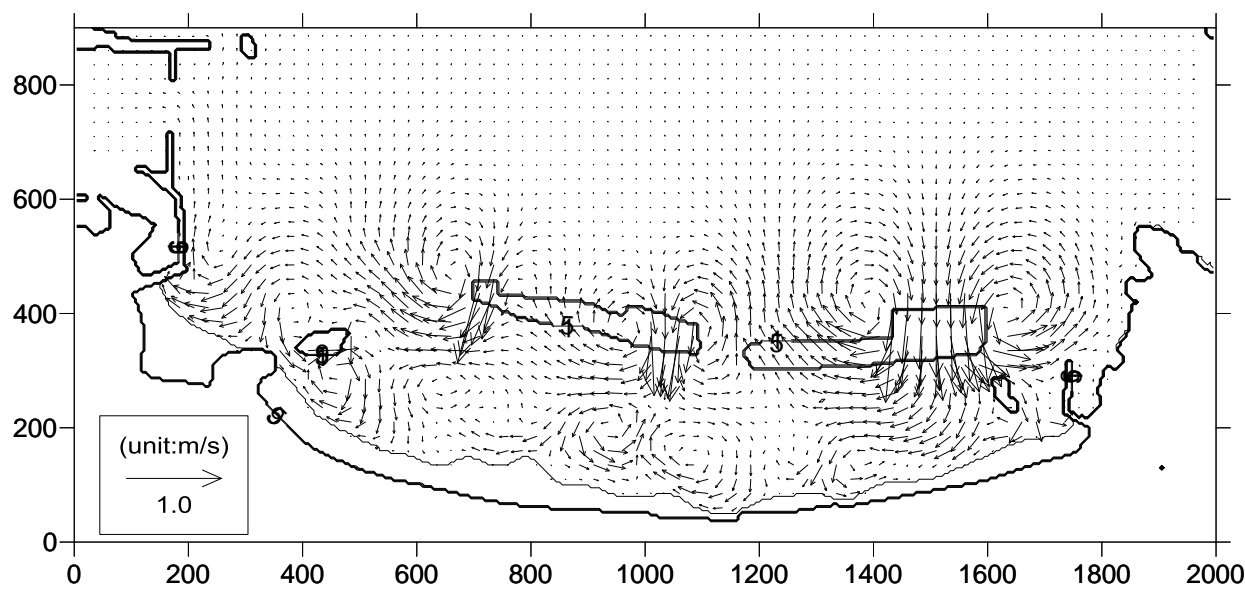

(a) Step1 $(\mathrm{Hs}=1.4 \mathrm{~m}, \mathrm{Ts}=6.7 \mathrm{~s})$

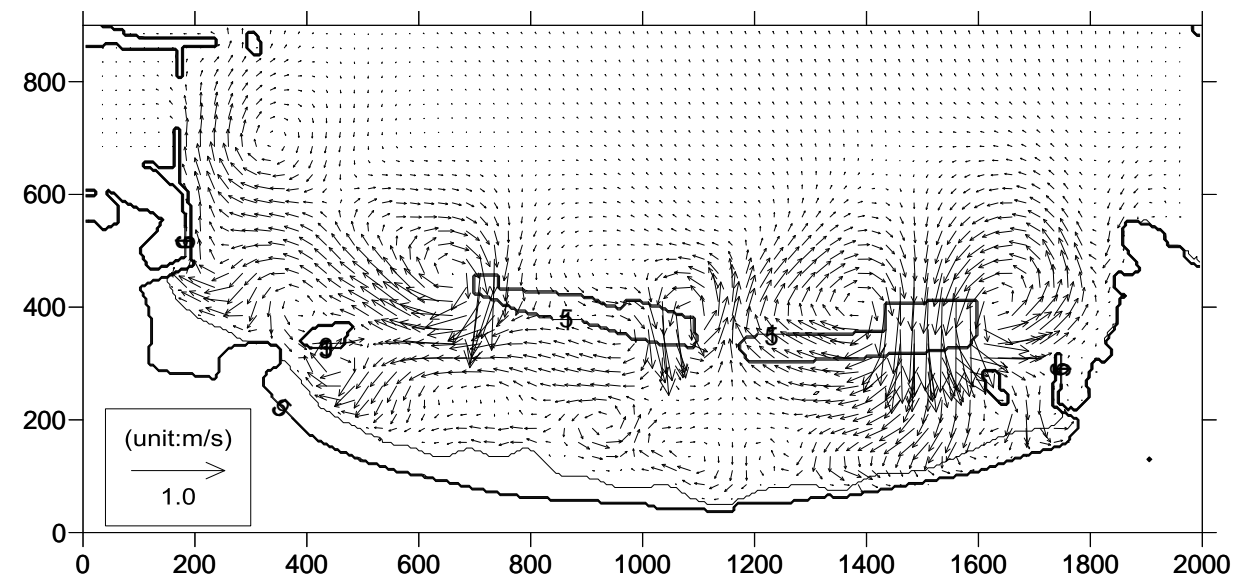

(b) Step3 (Hs=2.4m, Ts=7.1s)

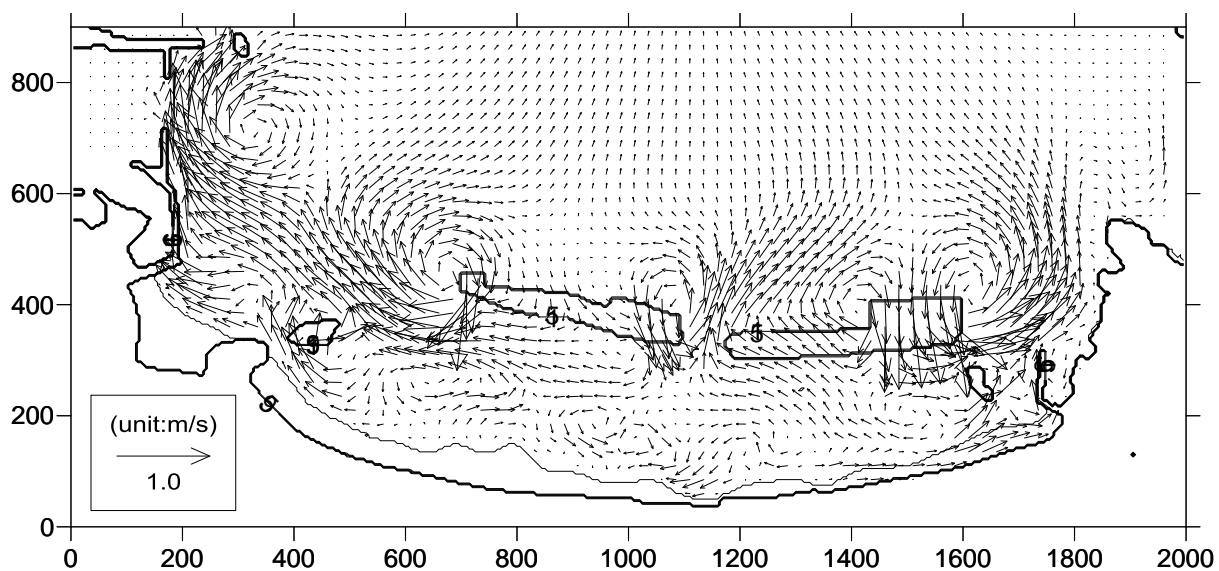

(c) Step4 (Hs=3.7m, Ts=9.7s)

Figure 11. Computed results of neashore current. 


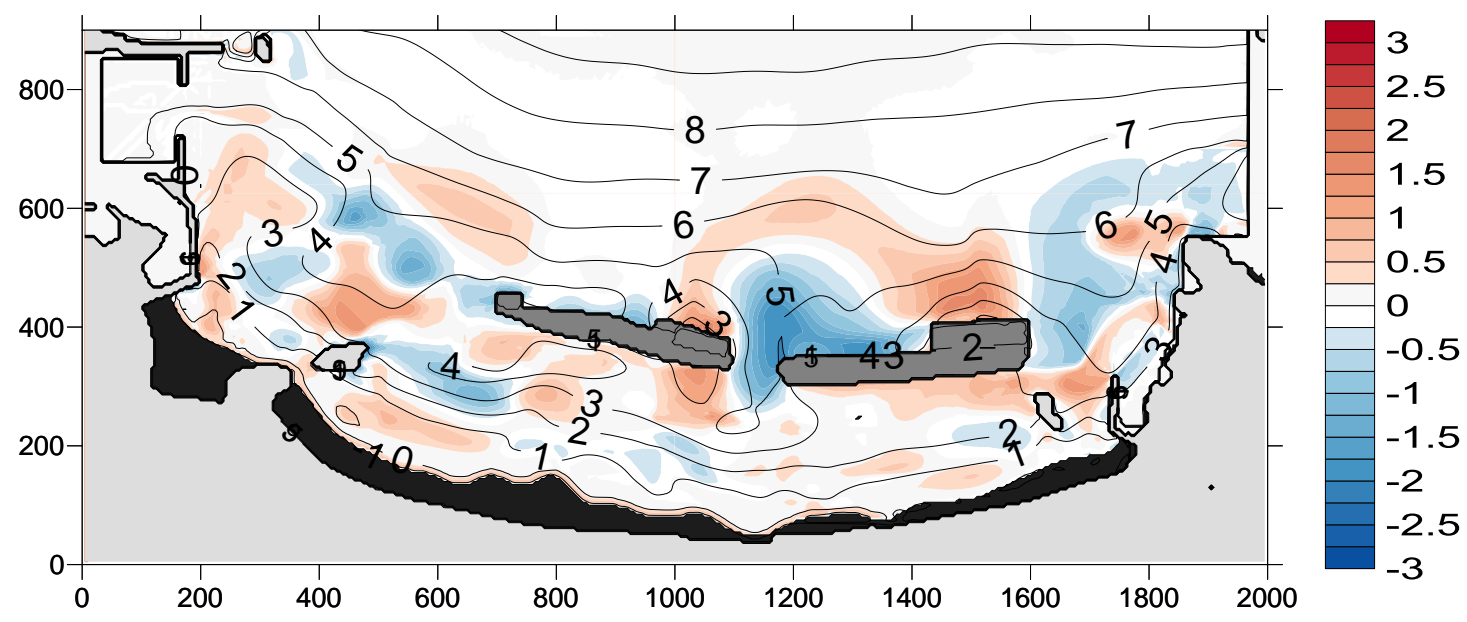

Figure 11. Computed bathymetry change after 6 months.

\section{REFERENCES}

De Vriend, H.J., J. Zyserman, J. Nicholson, J.A. Roelvink, P. Pechon, and H.N. Southgate. 1993. Medium-term 2DH coastal area modeling, Coastal Engineering, 21, 193-224.

Chawla, A., and Kirby, J.T. 2002. Monochromatic and random wave breaking at blocking points. Journal of Geophysical Research, 107, No. C7.

Dally, W.R. and Brown, Ch.A. 1995. A modeling investigation of the breaking wave roller with application to cross-shore currents. Journal of Geophysical Research, 100, No. C12, pp.873-883.

Kuroiwa, M., Matsubara, Y., Kuchiishi, T., Kato, K., Noda, H. and Son, C.B. A 2002. Morphodynamic model based on Q-3D nearshore current model and application to barred beach. The Proceedings of the 28th International Conference on Coastal Engineering, pp.3409-3421.

Kuroiwa,M, J.W.Kamphuis, T. Kuchiishi and Y. Matsubara. 2004. A 3D morohodynamice model with shoreline change based on quasi-3D nearshore current model, Proceedings of $29^{\text {th }}$ International Conference on Coastal Engineering, ASCE,

Kuroiwa, M., T. Kuchiishi and Y. Matsubara. 2006. Prediction System of 3D Beach Evolution with 2DH and Q3D Hydrodynamic Modes, Proceedings of $16^{\text {th }}$ International Offshore and Polar Engineering Conference, 751-757.

Kuroiwa,M., T. Kuchiishi, K.Kato, S. Sunagawa and Y. Matsubara. 2008. Applicability of coastal area model to morphodynamic around river mouth, Proceedings of $31^{\text {st }}$ International Conference on Coastal Engineering, ASCE, 2218-2230..

Kuroiwa,M.,Y. Shibutani , Y. Matsubara,T.Kuchiishi and M. Abualtyef. 2010. Numerical model of 3D morphodynamic after offshore nourishment, Proceedings of The International Conference On Coastal Engineering, No. 32, Shanghai,China. Paper \#:sediments.55. Retrieved from http://journals.tdl.org/ICCE/.

Mase, H., Yuhi, M., Amamori, H., and Takayama, T. 2004. Phase Averaging wave prediction model with breaking and diffraction effects in wave-current coexisting field. Annual Journal of Coastal Engineering, JSCE., 51, No.1, pp.6-10. (In Japanese).

Nishimura, H. 1988. Computation of nearshore current, nearshore dynamics and coastal process Theory, Measurements and Predictive Models, University of Tokyo Press, pp.271-291.

Sawaragi, T., Lee, J.S. and I. Deguchi. 1986. A new model for prediction of beach deformation around river mouth, Proceedings of International Symposium on Ocean Space Utilization, 85, 229-236.

Shimizu,T., A. Yamada and A. Watanabe. 1996. Coefficient and cross-shore distribution of alongshore sediment transport rate, Proceedings of Coastal Engineering, JSCE, Vo.43, 571-575.(in Japanese)

Zheng, J., Mase, H., Demirbilek, Z., and Lin, Li 2008. Implementation and evaluation of alternative wave breaking formula in a costal spectral wave model. Ocean Eng, 35, pp.1090-1101. 